\title{
Influence of freezing temperature before freeze-drying on the viability of various Lactobacillus plantarum strains
}

\author{
Guang-Qiang Wang, $\odot$ Jing Pu, $\odot$ Xiao-Qing Yu, $\odot$ Yong-Jun Xia, $\odot$ and Lian-Zhong Ai* $\odot$ \\ Shanghai Engineering Research Center of Food Microbiology, School of Medical Instrument and Food Engineering, \\ University of Shanghai for Science and Technology, Shanghai 200093, China
}

\begin{abstract}
Although freeze-drying is an excellent method for preserving microorganisms, it inevitably reduces cell activity and function. Moreover, probiotic strains differ in terms of their sensitivity to the freeze-drying process. Therefore, it is necessary to optimize the variables relevant to this process. The pre-freezing temperature is a critical parameter of the freeze-drying process, but it remains unclear whether the optimal pre-freezing temperature differs among strains and protectants. This study explored the effects of 4 different pre-freezing temperatures on the survival rates of different Lactobacillus plantarum strains after freeze-drying in the presence of different protectants. Using phosphate-buffered saline solution and sorbitol as protectants, pre-freezing at $-196^{\circ} \mathrm{C},-40^{\circ} \mathrm{C}$, and $-20^{\circ} \mathrm{C}$ ensured the highest survival rates after freeze-drying for AR113, AR307, and WCFS1, respectively. Using trehalose, pre-freezing at $-20^{\circ} \mathrm{C}$ ensured the best survival rate for AR113, and $-60^{\circ} \mathrm{C}$ was the best pre-freezing temperature for AR307 and WCFS1. These results indicate that the pre-freezing temperature can be changed to improve the survival rate of L. plantarum, and that this effect is strain-specific. Further studies have demonstrated that pre-freezing temperature affected viability via changes in cell membrane integrity, membrane permeability, and lactate dehydrogenase activity. In summary, pre-freezing temperature is a crucial factor in $L$. plantarum survival after freeze-drying, and the choice of pre-freezing temperature depends on the strain and the protectant.
\end{abstract}

Key words: freeze-drying, pre-freezing temperature, protectants, Lactobacillus plantarum

Received September 30, 2019.

Accepted November 28, 2019.

*Corresponding author: ailianzhong@hotmail.com

\section{INTRODUCTION}

Lactic acid bacteria (LAB) are commonly used as fermentation starters and probiotics, and are thus highly important to the food and dairy industries (Velly et al., 2015). They are also associated with various potential health benefits (Damaskos and Kolios, 2008; Lee et al., 2018) and have been studied widely to explore their potential effects on various digestive diseases (Gareau et al., 2010; Fan et al., 2019), chronic kidney disease (Koppe et al., 2015), immunomodulation (Ohtsuka et al., 2012), and blood cholesterol reduction (Nguyen et al., 2007; Korcz et al., 2018). However, the wide application of Lactobacillus spp. is dependent on the biological stability of these probiotics during long-term storage. Freeze-drying (i.e., lyophilization), which is widely used in the industrial production of LAB powder, is currently the most effective method for maintaining the stability of Lactobacillus (Li et al., 2011).

Freeze-drying is a form of cold-drying preservation in which a substance is dehydrated by sublimation. This process involves 3 phases: freezing, primary drying, and secondary drying (Fissore et al., 2019). Freeze-drying is the preferred long-term preservation method used at microbial resource centers and in the industrial production of bacterial starters (Prakash et al., 2013). In addition to its lower storage and transportation costs and easier handling than freezing (Santivarangkna et al., 2008; Velly et al., 2015), freeze-drying also helps to maintain the stability of products such as medications during production and extends the shelf life of finished products.

Freeze-drying has many advantages and is among the best methods for microorganism preservation. However, some aspects of this method require improvement. The long-term exposure of cells to extreme environments during freeze-drying has various effects on cell membrane integrity (Dianawati et al., 2016; Wang et al., 2019) and fluidity (Oldenhof et al., 2005; Schwab et al., 2007 ), and on the structures of sensitive proteins (Li et al., 2011; Kandil and El Soda, 2015). Inevitably, these changes induce physiological damage and reduce the activities and functions of cells. Moreover, the process- 
ing parameters, including freezing-thawing conditions, sample temperature, and pre-freezing temperature, must be optimized for each probiotic strain to account for differences in sensitivity to the freeze-drying process (Polo et al., 2017; Wang et al., 2019).

Cell damage during freeze-drying is attributable mainly to ice crystal formation, macromolecule denaturation, and high osmolarity-induced membrane damage due to the removal of water and high concentrations of internal solutes (Fonseca et al., 2000; Fowler and Toner, 2005; Mills et al., 2011). The main stages during freezedrying include control of the sample temperature, determination of the drying process, regulation of the pre-freezing temperature and cooling rate, and selection of the protectant type and concentration. To date, most research related to the freeze-drying of probiotics has focused on the effects of protectants (Martos et al., 2007; Li et al., 2011; Chen et al., 2017; Wang et al., 2019); few studies have focused on the pre-freezing temperature.

During the freeze-drying process, the sample is initially frozen and the sample is dried by sublimating the water or converting it directly from ice to vapor under a vacuum. During the sublimation phase, the sample must be kept frozen to ensure a product with good properties. If the pre-freezing temperature is not sufficiently low, the sample will not be frozen completely, and it will expand and foam during the process of sublimation under a vacuum. However, an excessively low pre-freezing temperature not only increases energy consumption but also reduces the survival rates of some microorganisms after freeze-drying. Polo et al. (2017) studied the influence of freezing temperature before freeze-drying on the viability of yeast and LAB isolated from wine and demonstrated that this parameter was crucial for ensuring the good survival of these microorganisms. Pre-freezing temperature is an important parameter of lyophilization that must be strictly controlled, but it remains unclear whether the optimal prefreezing temperature varies among $L$. plantarum stains.

This study aimed to investigate the influence of various freezing temperatures before vacuum drying on the subsequent survival of $L$. plantarum and to identify the optimal pre-freezing temperatures required to achieve the best survival rates of various $L$. plantarum strains. We also explored the effects of various protectants on freeze-drying, and evaluated the mechanism by which the pre-freezing temperature affects survival rate by analyzing membrane integrity and permeability and enzyme activity in the experimental $L$. plantarum strains. These results provide theoretical support for the rational selection of pre-freezing temperatures and consequent improvement of production processes.

\section{MATERIALS AND METHODS}

\section{Bacteria Strains and Culture Conditions}

Three L. plantarum strains were provided for these experiments by the Shanghai Engineering Research Centre of Food Microbiology, University of Shanghai for Science and Technology (Shanghai, China): L. plantarum AR113, L. plantarum AR307, and L. plantarum WCFS1. All L. plantarum strains were inoculated in MRS broth at $37^{\circ} \mathrm{C}$ for $12 \mathrm{~h}$ (Wang et al., 2019).

\section{L. plantarum Strain Biomass Production}

Each seed solution was inoculated into de Man, Rogosa, and Sharpe (MRS) liquid medium at a seeding rate of $1 \%$, and the culture was expanded at $37^{\circ} \mathrm{C}$. Once the culture had reached an optical density of 1 at $600 \mathrm{~nm}\left(\mathrm{OD}_{600}=1\right)$, a 2-mL aliquot was collected, pelleted by centrifugation at 7,378 $\times g$ for $5 \mathrm{~min}$, washed twice with sterile physiological saline solution, and centrifuged. The resulting bacteria mass was resuspended in $1 \mathrm{~mL}$ of trehalose $(100 \mathrm{~g} / \mathrm{L})$, sorbitol $(100 \mathrm{~g} / \mathrm{L})$, and PBS solution ( $\mathrm{pH} 6.5)$.

\section{Freeze-Drying and Determination of Survival Rate}

Each bacterial suspension was dispensed into a vial $(5 \mathrm{~mL})$. Next, the samples were subjected to different freezing treatments: $-20^{\circ} \mathrm{C},-40^{\circ} \mathrm{C}$ (freeze-drying equipment), $-60^{\circ} \mathrm{C}$, and $-196^{\circ} \mathrm{C}$ (liquid nitrogen) for $3 \mathrm{~h}$. Immediately after the treatment, the cells were placed in a freeze-drying apparatus and heated to $-30^{\circ} \mathrm{C}$ at a rate of $1^{\circ} \mathrm{C} / \mathrm{min}$, and held for $800 \mathrm{~min}$ to dry the sample. Next, the cells were heated to $25^{\circ} \mathrm{C}$ at a rate of $1^{\circ} \mathrm{C} / \mathrm{min}$, and held for $2 \mathrm{~h}$ as a secondary drying step. The vacuum was set to $20 \mathrm{~Pa}$ at a collection temperature of $-80^{\circ} \mathrm{C}$.

The total viable cell count in each samples was determined before freezing, after freezing for $3 \mathrm{~h}$, and after the freeze-drying process. Frozen cells were thawed at room temperature before the total cell count analysis. Freeze-dried cells were resuspended in $0.9 \mathrm{~mL}$ of sterile saline solution. All samples $(0.1 \mathrm{~mL})$ were diluted serially in sterile saline solution $(9 \mathrm{~g} / \mathrm{L} \mathrm{NaCl})$, plated on MRS agar plates, and cultured at $37^{\circ} \mathrm{C}$ for $48 \mathrm{~h}$. The survival rates (\%) after freezing, drying, and freezedrying were calculated and are expressed as $\mathrm{N}_{1} / \mathrm{N}_{0} \times$ $100 \%, \mathrm{~N}_{2} / \mathrm{N}_{1} \times 100 \%$, and $\mathrm{N}_{2} / \mathrm{N}_{0} \times 100 \%$, respectively, where $\mathrm{N}_{0}, \mathrm{~N}_{1}$, and $\mathrm{N}_{2}$ represent the numbers of viable cells before freezing, after freezing for $3 \mathrm{~h}$, and after freeze-drying, respectively. Three independent replicates were measured at each temperature. 


\section{Determination of Cell Membrane Integrity and Permeability}

The effect of freeze-drying on L. plantarum cell membrane integrity was determined using a double fluorescent staining process with fluorescein diacetate (FDA) and propidium iodide (PI). Samples obtained before and after lyophilization were washed with $1 \mathrm{~mL}$ of sterile PBS and resuspended in $850 \mu \mathrm{L}$ of PBS. Next, $100 \mu \mathrm{L}$ of FDA solution was added to yield a final concentration of $100 \mu \mathrm{g} / \mathrm{mL}$. The sample was mixed, and $50 \mu \mathrm{L}$ of PI was added to yield a final concentration of $50 \mu \mathrm{g} / \mathrm{mL}$. The suspension was shaken and incubated for $30 \mathrm{~min}$ at room temperature while protected from light. After washing the stained sample 3 times with PBS buffer, the cells were precipitated and resuspended in $500 \mu \mathrm{L}$ of PBS. The resulting bacterial solution was dropped on a glass slide and observed under a fluorescence microscope.

The effect of freeze-drying on L. plantarum cell membrane permeability was determined by single staining with fluorescein diacetate. Samples collected before and after lyophilization were washed with $1 \mathrm{~mL}$ of sterile PBS and resuspended in $1 \mathrm{~mL}$ of fresh PBS. Next, 150 $\mu \mathrm{L}$ of each bacterial suspension and $50 \mu \mathrm{L}$ of PI were mixed in the wells of a 96-well plate. A microplate reader was used to determine the level of fluorescence in each well.

\section{Preparation of Cell-Free Extract}

Each lyophilized sample was washed with $1 \mathrm{~mL}$ of PBS and resuspended in $1 \mathrm{~mL}$ of fresh PBS. Next, this bacterial suspension was disrupted ultrasonically in an ice water bath for 20 min. Each sonication cycle was set to $5 \mathrm{~s}$ on $/ 5 \mathrm{~s}$ off for 240 cycles. The cell debris was then removed by centrifugation at 7,378 $\times g$ and $4^{\circ} \mathrm{C}$ for $5 \mathrm{~min}$, and the supernatant was stored at $4^{\circ} \mathrm{C}$ before measurement of relevant enzyme activity levels.

\section{Lactate Dehydrogenase Assay}

Lactate dehydrogenase ( $\mathbf{L D H})$ reduces pyruvate to lactic acid, and its activity can be determined by the reduced absorption of NADH at $340 \mathrm{~nm}$. In this experiment, the total reaction volume of $0.31 \mathrm{~mL}$ contained $0.29 \mathrm{~mL}$ of sodium pyruvate solution, $0.01 \mathrm{~mL}$ of NADH solution, and $0.01 \mathrm{~mL}$ of cell-free extract. The absorption value of each reaction at $340 \mathrm{~nm}$ was measured using a microplate reader after shaking. Measurements were recorded every minute during 5 -min periods. By plotting time as the abscissa and absorption as the ordinate, the initial linear relationship was determined and used to calculate the reduction in NADH absorp- tion per minute. The specific activity is expressed per milligrams of protein.

\section{Assay of Pyruvate Kinase}

Pyruvate kinase activity in the samples was determined using a pyruvate kinase assay kit (Nanjing Jiancheng Bioengineering Institute, Nanjing, China). The specific activity was expressed per milligram of protein.

\section{Statistical Analysis}

Statistical analyses were performed using Origin 8.5 (OriginLab, Northampton, MA) and SPSS (IBM Corp., Armonk, NY). We examined significant differences between the data using single-factor and multi-factor methods. A $P$-value $<0.05$ indicated a statistically significant difference.

\section{RESULTS}

\section{Survival Rates of Different Strains Using Sorbitol as a Protectant}

Three L. plantarum strains were freeze-dried after exposure to various pre-freezing temperatures in the presence of sorbitol, and the survival rates after freezing, drying, and freeze-drying were determined (Figures 1, 2 , and 3 ). The effects of the 4 pre-freezing temperatures varied widely among the strains, but the effect of this variable also varied among the phases of freeze-drying for each strain.

As shown in Figure 1, strains AR113, AR307, and WCFS1 all exhibited higher freezing survival rates at $-20^{\circ} \mathrm{C}$ and $-40^{\circ} \mathrm{C}$. In all 3 strains, the maximum survival rate was obtained at $-20^{\circ} \mathrm{C}(70.6 \pm 2.37$, $85.8 \pm 1.11$, and $82.2 \pm 2.63 \%$, respectively). However, the 3 strains of L. plantarum differed in terms of the pre-freezing temperature associated with the lowest survival rate. We found that AR113 exhibited a worse survival response to freezing at $-60^{\circ} \mathrm{C}(24.71$ $\pm 2.14 \%$, or one-third of the maximum) compared to AR307 and WCFS1 (73.98 \pm 5.06 and $79.07 \pm 2.33 \%$, respectively). The AR307 strain exhibited the lowest survival rate at $-196^{\circ} \mathrm{C}(10.29 \pm 0.38 \%$, or less than one-eighth the maximum), and WCFS1 exhibited the lowest survival rate at $-196^{\circ} \mathrm{C}$, although its relative decrease in survival rate was much less severe (half the maximum). These results suggest that AR307 is less resistant to low temperatures.

As shown in Figure 2, AR307 exhibited dry survival rates of less than $10 \%$, regardless of the pre-freezing temperature. For AR113 and WCFS1, the highest dry 


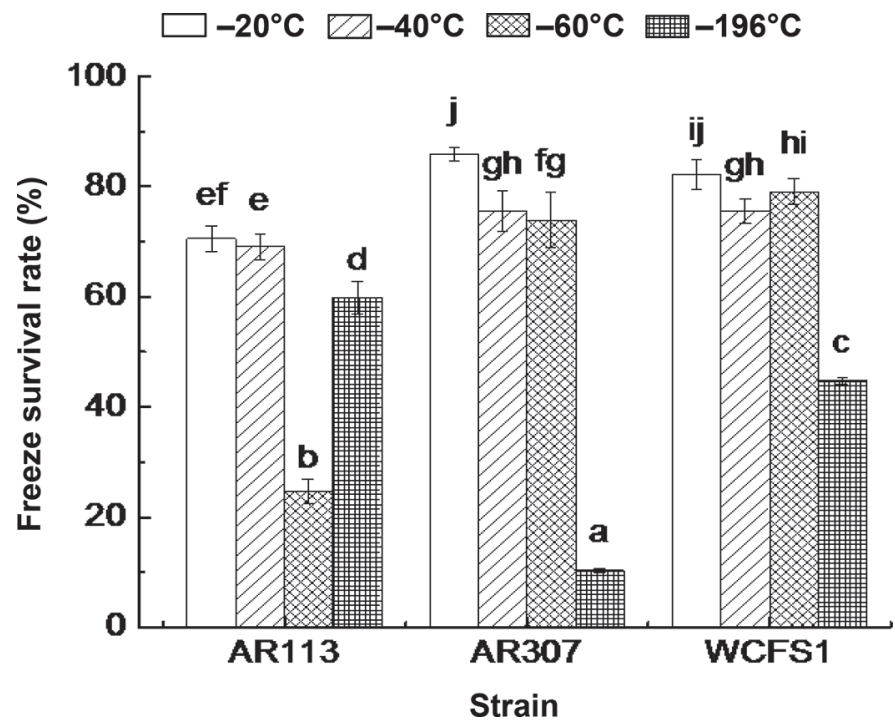

Figure 1. Freezing survival rates of Lactobacillus plantarum AR113, AR307, and WCFS1 after exposure to various pre-freezing temperatures. Data are presented as means of triplicates \pm SD. Means with different letters differ significantly $(P<0.05)$.

survival rates were obtained at $-60^{\circ} \mathrm{C}$ and $-196^{\circ} \mathrm{C}$, respectively, in contrast to the survival outcomes after freezing. These rates were 3 and 4 times higher, respectively, than the corresponding dry survival rates at $-40^{\circ} \mathrm{C}$. During the drying stage, WCFS1 exhibited a survival rate of $76.55 \pm 1.01 \%$ at $-196^{\circ} \mathrm{C}$, whereas AR113 and AR307 exhibited survival rates of less than

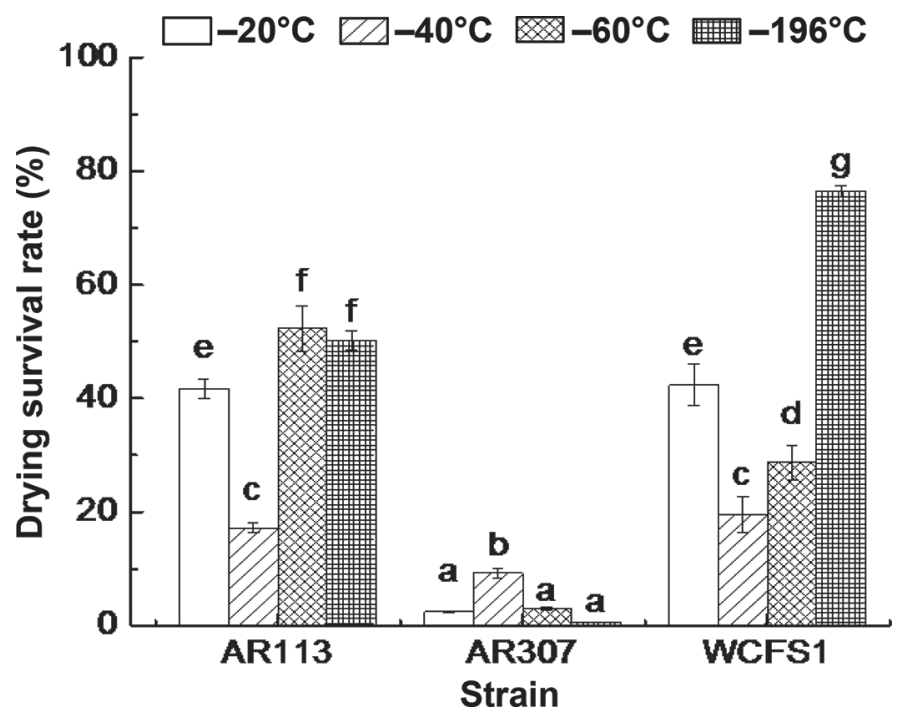

Figure 2. Drying survival rates of Lactobacillus plantarum AR113, AR307, and WCFS1 after exposure to various pre-freezing temperatures. Data are presented as means of triplicates \pm SD. Means with different letters differ significantly $(P<0.05)$.

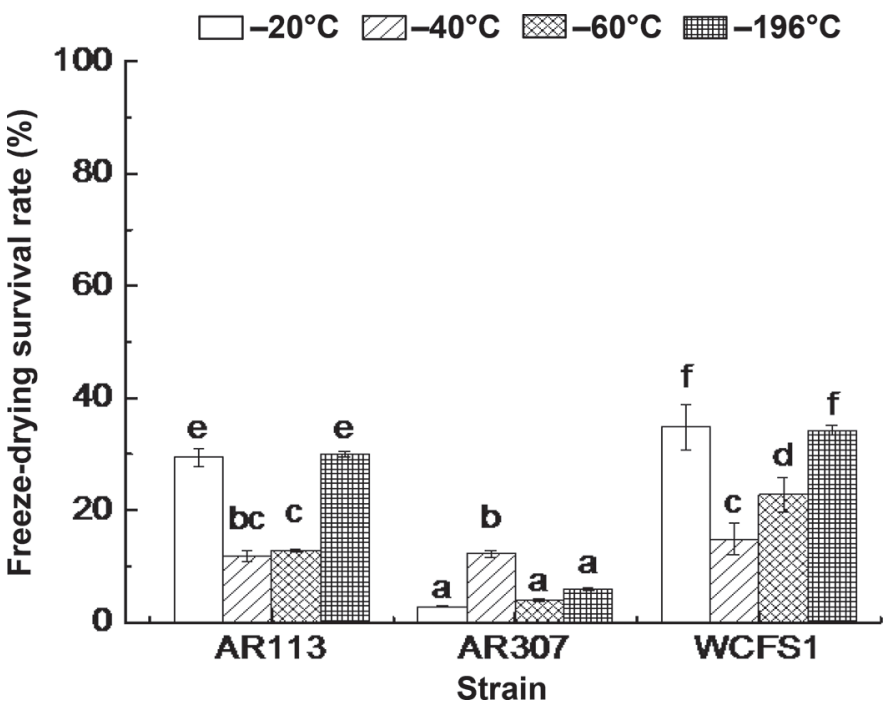

Figure 3. Freeze-drying survival rates of Lactobacillus plantarum AR113, AR307, and WCFS1 after exposure to various pre-freezing temperatures. Data are presented as means of triplicates \pm SD. Means with different letters differ significantly $(P<0.05)$.

$50 \%$. In summary, most of the damage associated with freeze-drying may occur during the drying stage.

Figure 3 reflects the freeze-drying survival rates associated with 4 pre-freezing temperatures. The AR113 and WCFS1 strains achieved maximum survival rates at $-20^{\circ} \mathrm{C}$ and $-196^{\circ} \mathrm{C}$, respectively, and these rates were 2.3 to 2.5 times higher than these observed at $-40^{\circ} \mathrm{C}$. The AR307 strain exhibited low survival rates at all 4 pre-freezing temperatures. In AR307, the highest survival rate was achieved at $-40^{\circ} \mathrm{C}$, approximately 4.3 times higher than the lowest survival rate achieved at $-20^{\circ} \mathrm{C}$. Although the pre-freezing temperature could be changed to improve the freeze-drying survival rate of all 3 L. plantarum strains in the presence of sorbitol, the overall outcomes were poor. Therefore, we explored various protectants to identify conditions better suited to survival.

\section{Survival of Strains Under Different Protectants}

We determined the survival rates of $L$. plantarum strains in the presence of various pre-freezing temperatures and protectants (Figures 4, 5, and 6). Compared with PBS and sorbitol, trehalose significantly improved the survival rates of $L$. plantarum strains after freezing, drying, and freeze-drying at the 4 pre-freezing temperatures. In particular, trehalose yielded the highest AR113 survival rate after freeze-drying, which was 1.44 times higher than the rate achieved with sorbitol (Figure 6A). We also observed similar results for AR307 and WCFS1 when exposed to trehalose, for which the 
highest survival rates were 8.42 and 2.26 times higher, respectively, than those achieved with sorbitol (Figure $6 \mathrm{~B}-\mathrm{C})$. For AR307, the overall highest freezing survival rate of $85.8 \%$ was achieved in the presence of sorbitol, but trehalose was the superior protectant in terms of the freeze-drying survival rate.

As shown in Figure 4, the various strains of LAB all exhibited higher freezing survival rates in the presence of various protectants at $-20^{\circ} \mathrm{C}$. The survival rates of AR113 (Figure 4A), AR307 (Figure 4B), and WCFS1 (Figure $4 \mathrm{C}$ ) in response to a change in the pre-freezing temperature were increased by $2.86,8.35$, and 1.84 times, respectively, in the presence of sorbitol and by $1.47,3.10$, and 1.38 times, respectively, in the presence of trehalose. These results demonstrate that trehalose was associated with a lower fluctuating survival rate margin induced by temperature regulation than sorbitol. Accordingly, the survival rate of $L$. plantarum can be improved by changing the pre-freezing temperature.

The effects of various pre-freezing temperatures on the drying survival rates of L. plantarum strains are demonstrated in Figure 5. Here, the partial drying survival rates were significantly lower than the freezing survival rates, again suggesting that the drying stage may be the most important in terms of cell injury.

Figure 6 reflects significant differences in optimal treatment temperatures among the various strains in the presence of the same protectants. The optimal treatment temperatures also varied within strains in the presence of various protectants. With PBS and sorbitol, freezing at $-196^{\circ} \mathrm{C}$ ensured the best survival rate for AR113 (Figure 6A), whereas $-40^{\circ} \mathrm{C}$ and $-20^{\circ} \mathrm{C}$ were the optimal temperatures for AR307 (Figure 6B) and WCFS1 (Figure 6C), respectively. With trehalose, freezing at $-20^{\circ} \mathrm{C}$ ensured the best survival rate for AR113, whereas $-60^{\circ} \mathrm{C}$ was the optimal treatment temperature for both AR307 and WCFS1. The strains also exhibited significant differences in survival rates at the 4 temperatures. In the presence of trehalose, a change in the pre-freezing temperature led to maximum increases in survival rates of 1.25 and 1.67 times for AR113 and WCFS1 and a maximum increase of 6.56 times for AR307 (Figure 6).

In summary, trehalose yielded significant improvements relative to PBS and sorbitol in the survival rates of $L$. plantarum strains at 4 pre-freezing temperatures. The data indicate that trehalose is the superior protectant in this context. In addition, although the survival rates of all tested L. plantarum strains could be improved by changing the pre-freezing temperature, we observed significant inter-strain differences, especially for AR307. This finding suggests that the effect of prefreezing temperature on the freeze-drying survival rate is strain-specific.
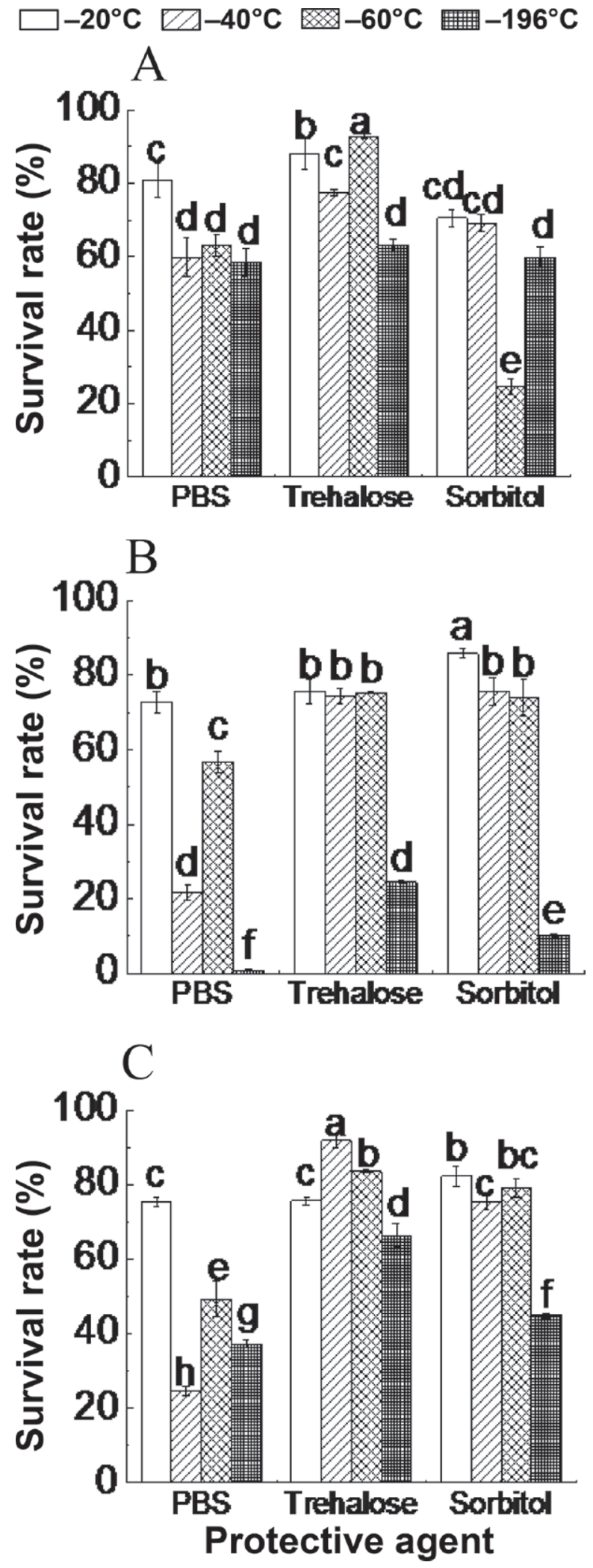

Figure 4. Freezing survival rates of Lactobacillus plantarum (A) AR113, (B) AR307, and (C) WCFS1 exposed to various protectants and freezing temperatures. Data are presented as means of triplicates \pm SD. Means with different letters differ significantly $(P<0.05)$. 
$-20^{\circ} \mathrm{C}-40^{\circ} \mathrm{C}-60^{\circ} \mathrm{C}$ 曲 $-196^{\circ} \mathrm{C}$
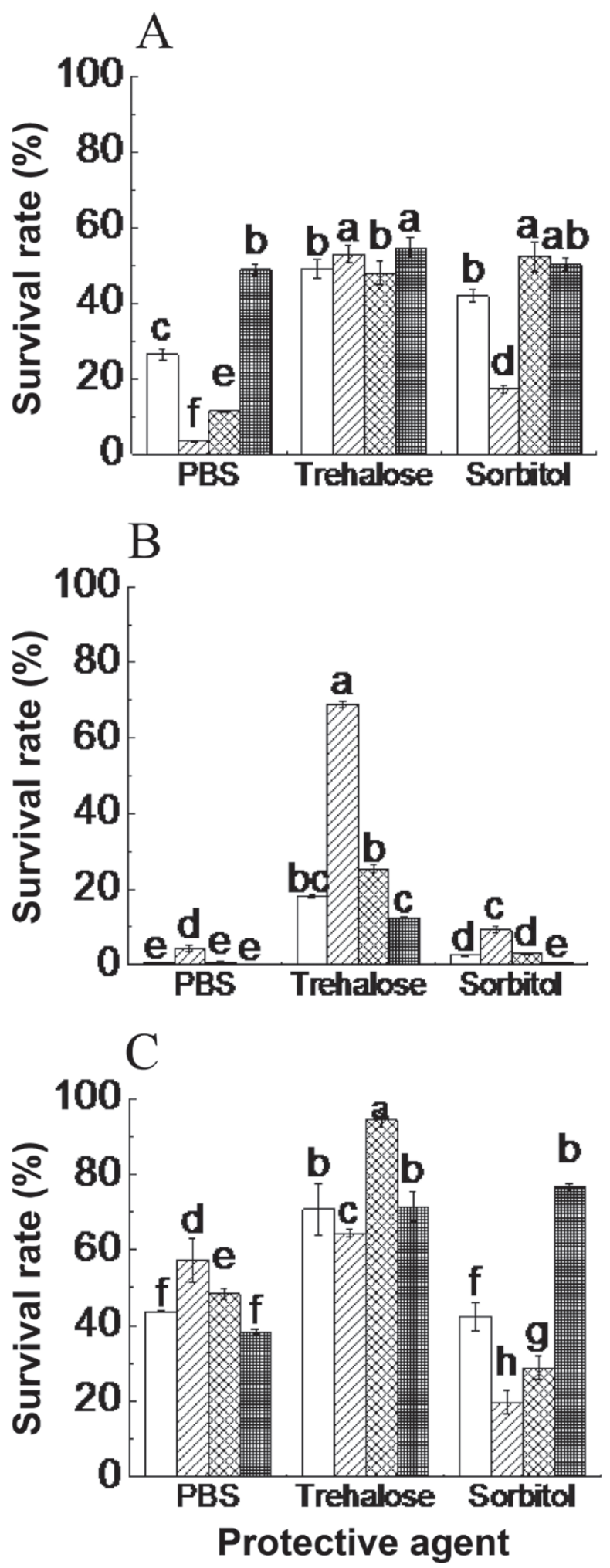

Figure 5. Drying survival rates of Lactobacillus plantarum (A) AR113, (B) AR307, and (C) WCFS1 exposed to various protectants and freezing temperatures. Data are presented as means of triplicates \pm SD. Means with different letters differ significantly $(P<0.05)$. $\square-20^{\circ} \mathrm{C} \square-40^{\circ} \mathrm{C}-60^{\circ} \mathrm{C}$ 曲 $-196^{\circ} \mathrm{C}$
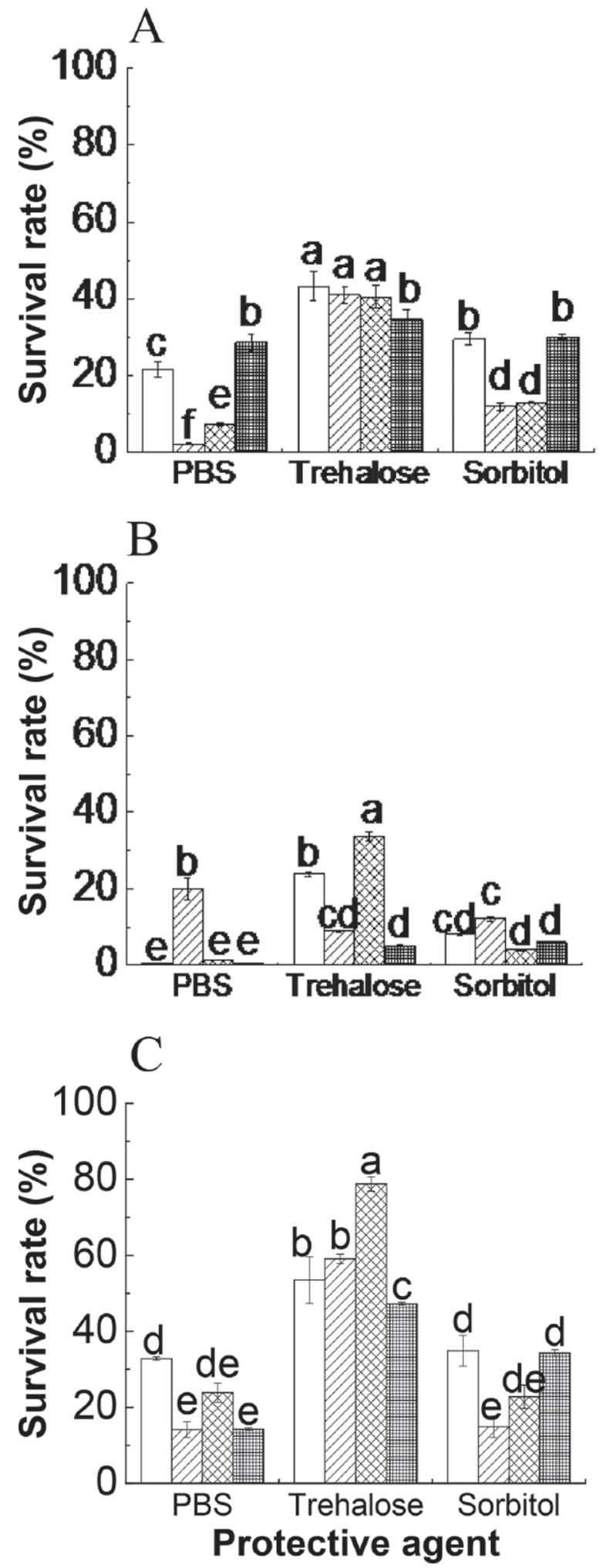

Figure 6. Freeze-drying survival rates of Lactobacillus plantarum (A) AR113, (B) AR307, and (C) WCFS1 exposed to various protectants and freezing temperatures. Data are presented as means of triplicates $\pm \mathrm{SD}$. Means with different letters differ significantly $(P<0.05)$. 

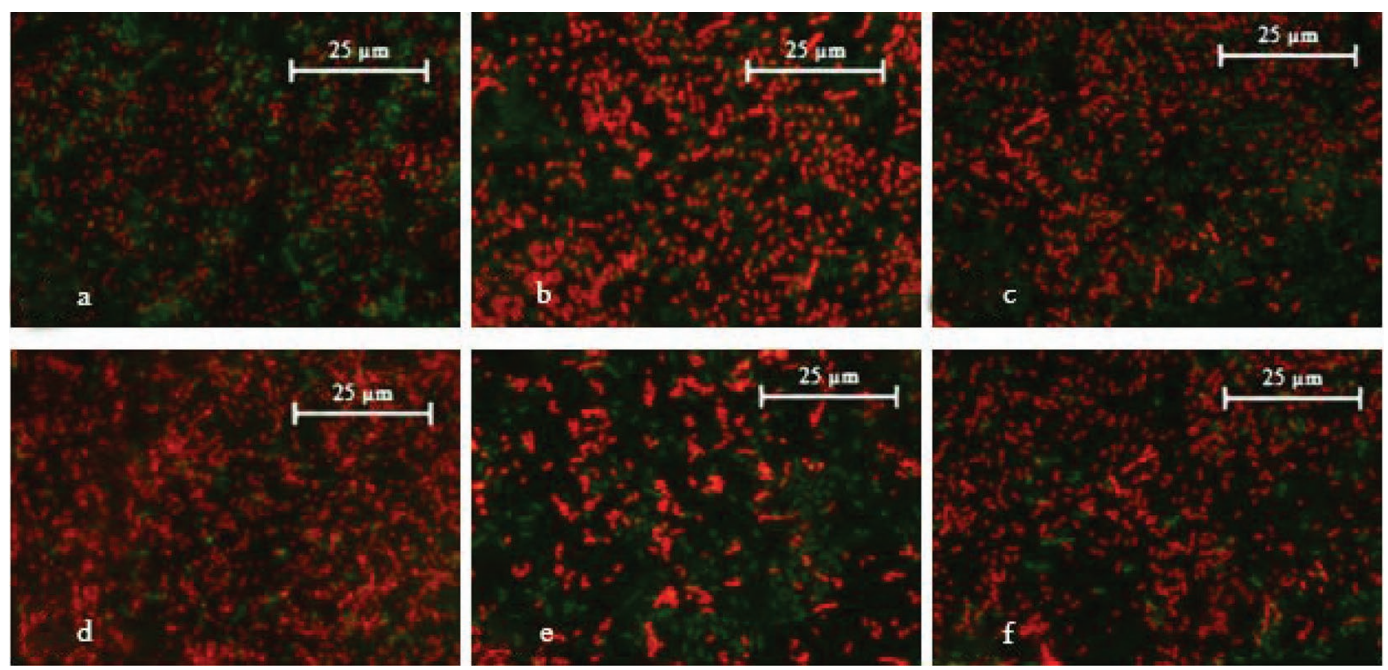

Figure 7. Effect of pre-freezing temperature on the integrity of the Lactobacillus plantarum (strains AR113, AR307, and WCFS1) cell membrane after freeze-drying. Bacteria with intact cell membranes (viable cells) or damaged cell membranes (dead cells) emit green and red fluorescence, respectively. (a) AR 113 trehalose $-20^{\circ} \mathrm{C}$; (b) AR113 trehalose $-196^{\circ} \mathrm{C}$; (c) AR307 trehalose $-20^{\circ} \mathrm{C}$; (d) $\mathrm{AR} 307$ trehalose $-196^{\circ} \mathrm{C}$; (e) WCFS1 trehalose $-20^{\circ} \mathrm{C}$; (f) WCFS1 trehalose $-196^{\circ} \mathrm{C}$.

\section{Mechanism Underlying the Effects of Pre-Freezing Temperature on Survival}

Figure 7 presents fluorescence images of the $3 \mathrm{~L}$. plantarum strains stained with FDA and PI after exposure to various pre-freezing temperatures. In the images, bacteria with intact cell membranes (i.e., viable cells) emit green fluorescence, and those with damaged cell membranes (i.e., dead cells) emit red fluorescence. Exposure to a pre-freezing temperature of $-196^{\circ} \mathrm{C}$ led to significant increases in the density of cell membrane damage relative to the damage observed at $-20^{\circ} \mathrm{C}$ in all 3 L. plantarum strains (Figure 7), especially AR307. These data suggest that cell membrane damage is an important cause of death during freeze-drying, and that this damage could be reduced by changing the pre-freezing temperature. In particular, an appropriate pre-freezing temperature would enable the formation of more uniform ice crystals and reduce damage to the cell membrane.

The $3 \mathrm{~L}$. plantarum strains were also stained with FDA alone, and we used the fluorescence of these cells after freeze-drying as an indicator of cell membrane permeability. Specifically, high fluorescence indicated minor cell membrane damage, and low fluorescence indicated more serious damage. We then determined the permeability of $3 \mathrm{~L}$. plantarum species exposed to various pre-freezing temperatures. As shown in Figure 8, we observed better membrane permeability $-20^{\circ} \mathrm{C}$ than at $-196^{\circ} \mathrm{C}$, consistent with survival rates. For example, the fluorescence of AR113 at $-20^{\circ} \mathrm{C}$ was $44 \%$ (Figure $6 \mathrm{~A}$ ), nearly 1.3 times higher than that at $-196^{\circ} \mathrm{C}$. These results suggest that more serious cell membrane damage occurred at $-196^{\circ} \mathrm{C}$ than at $-20^{\circ} \mathrm{C}$, consistent with the results of the cell membrane integrity analysis.

Lactate dehydrogenase catalyzes the conversion of lactate to pyruvate, an important step in energy production in LAB cells. The activity of this enzyme tends to decrease after freezing or freeze-drying. Therefore, $\mathrm{LDH}$ is used as a model protein for distinguishing the protective effects of solutes against freezing and drying-induced denaturation (Carpenter et al., 1993;

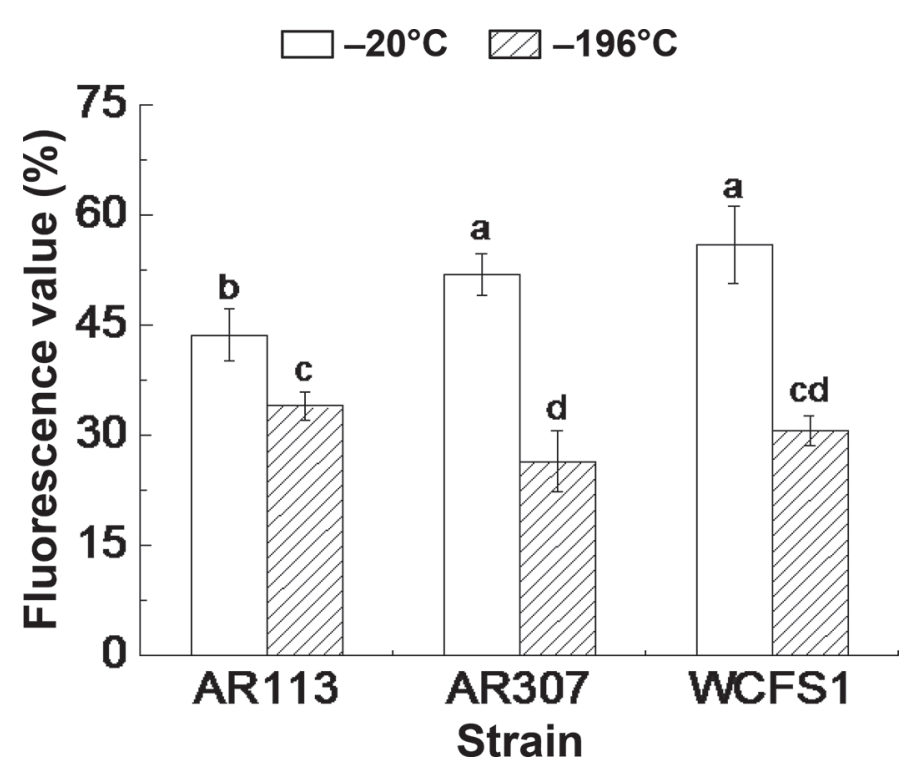

Figure 8. Membrane permeability of Lactobacillus plantarum AR113, AR307, and WCFS1 after freezing. Data are presented as means of triplicates \pm SD. Means with different letters differ significantly $(P<0.05)$. 
Jiang and Nail, 1998). In the present study, the LDH activity levels in all strains were higher at $-20^{\circ} \mathrm{C}$ than at $-196^{\circ} \mathrm{C}$, and this phenomenon was more significant in AR307 (Figure 9a). These findings were consistent with the results of the cell membrane integrity and survival analyses. Lactate dehydrogenase is also a marker of plasma membrane integrity. High LDH activity indicates an intact cell membrane and ensures the survival of the strain. Therefore, appropriate pre-freezing temperature can increase the activity of LDH and ensure the viability of $L$. plantarum.

Pyruvate kinase is the key rate-limiting enzyme in glycolysis. In the present study, the activity of this enzyme was not significantly affected by differences in pre-freezing temperatures in any of the 3 strains (Figure $9 \mathrm{~b})$. In other words, the pre-freezing temperature did not affect pyruvate kinase activity in L. plantarum.

\section{DISCUSSION}

Freeze-drying can effectively maintain probiotic activity and is suitable for long-term preservation. This technique causes less damage to biological tissues and cell structures and features and effectively protects the stability and activity of probiotics. In probiotics, one of the most important intrinsic factors in the freezedrying survival rate is the type of microorganism, and one of most relevant extrinsic factors is the freezing protocol (Santivarangkna et al., 2008). The effects of most extrinsic factors, such as freezing rates, thawing temperatures, and the type and concentration of protectant during the pre-freezing process, are strainspecific. However, it is unclear whether the pre-freezing temperature is similarly strain-specific.

Many studies have explored agents that protect probiotics during lyophilization. According to Archacka et al. (2019), $10 \%$ trehalose yielded the best viability rate in $L$. lactis bacteria subjected to freeze-drying. Stefanello et al. (2019) studied the survival and stability of L. fermentum and Wickerhamomyces anomalus strains upon lyophilization with various cryoprotectant agents and also identified trehalose as one of the better protectants. These earlier findings are consistent with our research findings. In our study, sorbitol did not yield good effects as a protectant, whereas replacement with trehalose improved the survival rates of L. plantarum strains. Therefore, the protectant is an important contributor to improving survival in freeze-drying conditions.

In addition to protectant selection, an exploration of methods to improve the freeze-drying survival rate of probiotics may also be meaningful. In a previous study, freeze-dried L. plantarum powder was encapsulated in high internal phase emulsions stabilized with whey protein isolate microgels. Notably, the viability of encapsulated L. plantarum after pasteurization increased by a factor of approximately 1.8 (Su et al., 2018). Wang et al. (2019) reported that optimization of the freezing-thawing conditions improved the survival rate
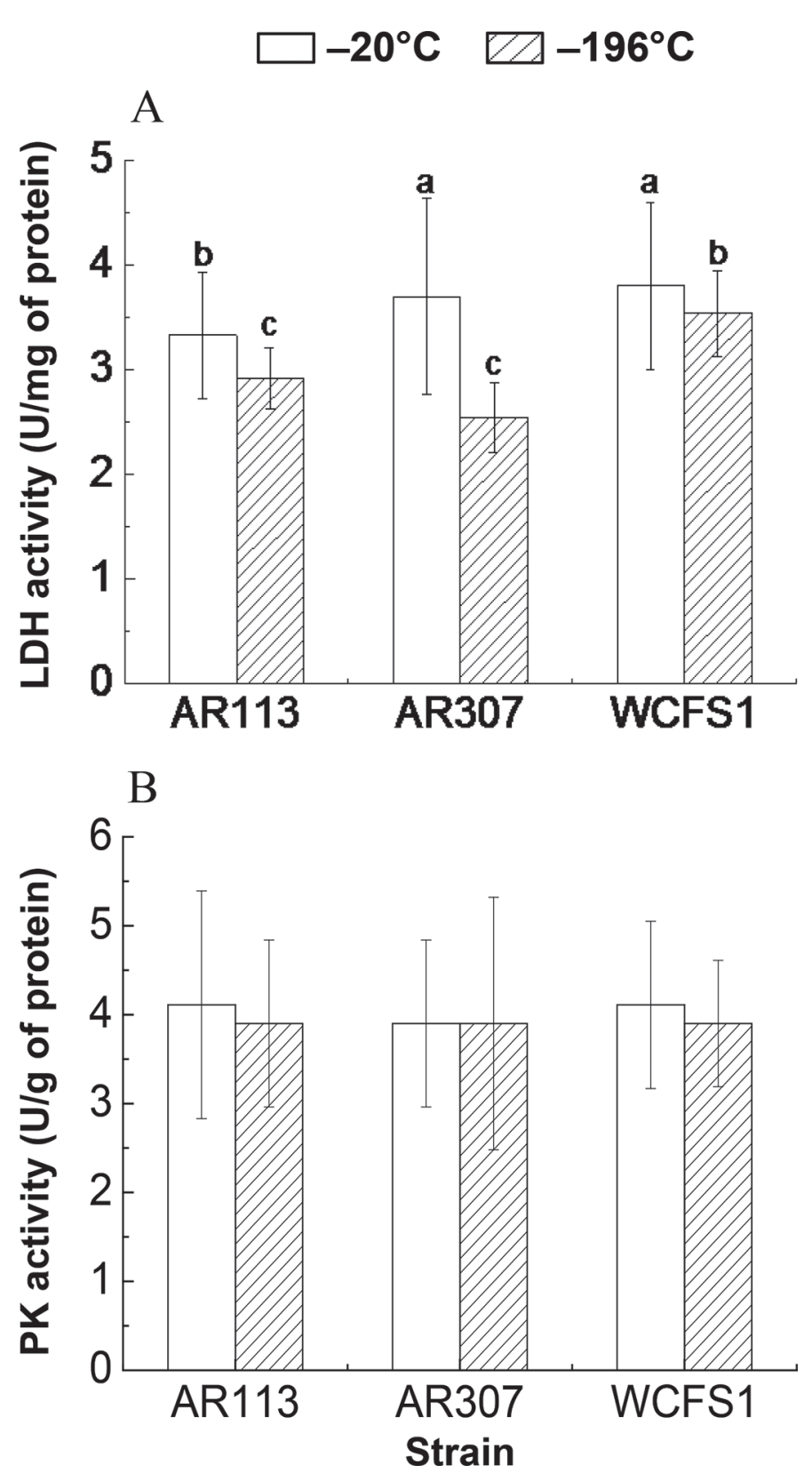

Figure 9. (A) Lactate dehydrogenase (LDH) activity levels in Lactobacillus plantarum AR113, AR307, and WCFS1 exposed to 4 pre-freezing temperatures. (B) Pyruvate kinase (PK) activity in the 3 L. plantarum strains exposed to different pre-freezing temperatures. Data are presented as means of triplicates $\pm \mathrm{SD}$. Means with different letters differ significantly $(P<0.05)$. 
of L. plantarum by almost 1.67 times. Izquierdo-López et al. (2017) improved the survival rate by subjecting freeze-dried samples to a foaming pre-treatment, which reduced the time required for freeze-drying by 7 -fold and improved the viability of Bifidobacterium longum RO175 by a maximum of 1.19 times. Polo et al. (2017) explored the effects of 3 freezing temperatures on the post-freeze-drying survival rates of wine yeasts and LAB. In that study, a change in the pre-freezing temperature improved the survival rate of $L$. plantarum by a factor of approximately 1.19.

Our study aimed to improve the freeze-drying survival rate of $L$. plantarum by altering the pre-freezing temperature. We observed major differences in the survival rates of various strains of $L$. plantarum at each tested pre-freezing temperature. When trehalose was used as a protectant, the survival rates of AR113 and WCFS1 increased by a maximum of 1.25 and 1.67 times, respectively, and that of AR307 increased by a maximum of 6.56 times after changing the pre-freezing temperature. Therefore, the survival rates of L. plantarum strains can be improved by changing the pre-freezing temperature, although the effect of this variable is strain-specific. $\mathrm{Li}$ et al. (2011) demonstrated that membrane integrity improved in the presence of $10 \%$ trehalose. Moreover, they also identified LDH and ATPases as key markers that could be used to evaluate the effects of cryoprotectants on the viability and metabolic activities of $L$. reuteri CICC6226 during freeze-drying. In the present study of L. plantarum, we found that cell membrane integrity, membrane permeability, and LDH enzyme activity improved in response to a change in the pre-freezing temperature, leading to a higher survival rate.

\section{CONCLUSIONS}

Freeze-drying is among the most common methods of probiotic preservation, but it inevitably induces physiological cell damage and reduces cell survival and function. Although protectants are used to mitigate this cell damage, the application of other processing parameters during freeze-drying should be considered. Our data demonstrate that the pre-freezing temperature is a crucial contributor to cell damage. Specifically, optimization of the pre-freezing temperature can significantly improve the survival rate of a probiotic strain. This finding provides another approach to the maintenance of probiotic viability. In addition, the optimal pre-freezing temperature is strain-dependent and must be based on the strains and protectants. Overall, our results provide another strategy for improving the viability of probiotic strains and provide theoretical support for the rational selection of the pre-freezing temperature during the freeze-drying process.

\section{ACKNOWLEDGMENTS}

This work was supported by the National Key Research and Development Program of China (No. 2018YFD0501600), the National Natural Science Foundation of China (No. 31972056), and the Shanghai Agriculture Applied Technology Development Program, China (Grant No. 2019-02-08-00-07-F01152). The authors do not have any conflicts of interest.

\section{REFERENCES}

Archacka, M., W. Bialas, R. Dembczynski, A. Olejnik, A. Sip, D. Szymanowska, E. Celinska, T. Jankowski, A. Olejnik, and M. Rogodzinska. 2019. Method of preservation and type of protective agent strongly influence probiotic properties of Lactococcus lactis: A complete process of probiotic preparation manufacture and use. Food Chem. 274:733-742. https://doi.org/10.1016/j.foodchem .2018.09.033.

Carpenter, J. F., S. J. Prestrelski, and T. Arakawa. 1993. Separation of freezing- and drying-induced denaturation of lyophilized proteins using stress-specific stabilization. I. Enzyme activity and calorimetric studies. Arch. Biochem. Biophys. 303:456-464. https://doi .org/10.1006/abbi.1993.1309.

Chen, H., J. Huang, X. Shi, Y. Li, and Y. Liu. 2017. Effects of six substances on the growth and freeze-drying of Lactobacillus delbrueckit ssp. bulgaricus. Acta Sci. Pol. Technol. Aliment. 16:403-412.

Damaskos, D., and G. Kolios. 2008. Probiotics and prebiotics in inflammatory bowel disease: Microflora 'on the scope'. Br. J. Clin. Pharmacol. 65:453-467. https://doi.org/10.1111/j.1365-2125.2008 .03096.x.

Dianawati, D., V. Mishra, and N. P. Shah. 2016. Survival of microencapsulated probiotic bacteria after processing and during storage: A review. Crit. Rev. Food Sci. Nutr. 56:1685-1716. https://doi .org/10.1080/10408398.2013.798779.

Fan, H., J. Du, X. Liu, W. W. Zheng, Z. H. Zhuang, C. D. Wang, and R. Gao. 2019. Effects of pentasa-combined probiotics on the microflora structure and prognosis of patients with inflammatory bowel disease. Turk. J. Gastroenterol. 30:680-685. https://doi.org/ 10.5152/tjg.2019.18426.

Fissore, D., G. Gallo, A. E. Ruggiero, and T. N. Thompson. 2019. On the use of a micro freeze-dryer for the investigation of the primary drying stage of a freeze-drying process. Eur. J. Pharm. Biopharm. 141:121-129. https://doi.org/10.1016/j.ejpb.2019.05.019.

Fonseca, F., C. Beal, and G. Corrieu. 2000. Method of quantifying the loss of acidification activity of lactic acid starters during freezing and frozen storage. J. Dairy Res. 67:83-90. https://doi.org/10 $.1017 /$ S002202999900401X

Fowler, A., and M. Toner. 2005. Cryo-injury and biopreservation. Ann. N. Y. Acad. Sci. 1066:119-135. https://doi.org/10.1196/annals .1363 .010 .

Gareau, M. G., P. M. Sherman, and W. A. Walker. 2010. Probiotics and the gut microbiota in intestinal health and disease. Nat. Rev. Gastroenterol. Hepatol. 7:503-514. https://doi.org/10.1038/ nrgastro.2010.117.

Izquierdo-López, D., J. Goulet, and C. Ratti. 2017. Foam-mat freezefrying of Bifidobacterium longum RO175: viability and refrigerated storage stability. J. Food Sci. 82:90-96. https://doi.org/10.1111/ 1750-3841.13571

Jiang, S., and S. L. Nail. 1998. Effect of process conditions on recovery of protein activity after freezing and freeze-drying. Eur. J. Pharm. Biopharm. 45:249-257. https://doi.org/10.1016/S0939 $-6411(98) 00007-1$

Kandil, S., and M. El Soda. 2015. Influence of freezing and freeze drying on intracellular enzymatic activity and autolytic properties of some lactic acid bacterial strains. Adv. Microbiol. 05:371-382 https://doi.org/10.4236/aim.2015.56039. 
Koppe, L., D. Mafra, and D. Fouque. 2015. Probiotics and chronic kidney disease. Kidney Int. 88:958-966. https://doi.org/10.1038/ ki.2015.255.

Korcz, E., Z. Kerenyi, and L. Varga. 2018. Dietary fibers, prebiotics, and exopolysaccharides produced by lactic acid bacteria: Potential health benefits with special regard to cholesterol-lowering effects. Food Funct. 9:3057-3068. https://doi.org/10.1039/C8FO00118A.

Lee, E. S., E. J. Song, Y. D. Nam, and S. Y. Lee. 2018. Probiotics in human health and disease: From nutribiotics to pharmabiotics. J. Microbiol. 56:773-782. https://doi.org/10.1007/s12275-018 -8293-y.

Li, B., F. Tian, X. Liu, J. Zhao, H. Zhang, and W. Chen. 2011. Effects of cryoprotectants on viability of Lactobacillus reuteri CICC6226. Appl. Microbiol. Biotechnol. 92:609-616. https://doi.org/10.1007/ s00253-011-3269-4.

Martos, G. I., C. J. Minahk, G. Font de Valdez, and R. Morero. 2007. Effects of protective agents on membrane fluidity of freeze-dried Lactobacillus delbrueckii ssp. bulgaricus. Lett. Appl. Microbiol. 45:282-288. https://doi.org/10.1111/j.1472-765X.2007.02188.x.

Mills, S., C. Stanton, G. F. Fitzgerald, and R. P. Ross. 2011. Enhancing the stress responses of probiotics for a lifestyle from gut to product and back again. Microb. Cell Fact. 10(Suppl 1):S19. https: //doi.org/10.1186/1475-2859-10-S1-S19.

Nguyen, T. D., J. H. Kang, and M. S. Lee. 2007. Characterization of Lactobacillus plantarum $\mathrm{PH} 04$, a potential probiotic bacterium with cholesterol-lowering effects. Int. J. Food Microbiol. 113:358 361. https://doi.org/10.1016/j.ijfoodmicro.2006.08.015.

Ohtsuka, Y., T. Ikegami, H. Izumi, M. Namura, T. Ikeda, T. Ikuse, Y. Baba, T. Kudo, R. Suzuki, and T. Shimizu. 2012. Effects of Bifidobacterium breve on inflammatory gene expression in neonatal and weaning rat intestine. Pediatr. Res. 71:46-53. https://doi.org/ $10.1038 /$ pr.2011.11.

Oldenhof, H., W. F. Wolkers, F. Fonseca, S. Passot, and M. Marin. 2005. Effect of sucrose and maltodextrin on the physical properties and survival of air-dried Lactobacillus bulgaricus: An in situ Fourier transform infrared spectroscopy study. Biotechnol. Prog. 21:885-892. https://doi.org/10.1021/bp049559j.

Polo, L., R. Manes-Lazaro, I. Olmeda, L. E. Cruz-Pio, A. Medina, S. Ferrer, and I. Pardo. 2017. Influence of freezing temperatures prior to freeze-drying on viability of yeasts and lactic acid bacteria isolated from wine. J. Appl. Microbiol. 122:1603-1614. https://doi .org/10.1111/jam.13465.

Prakash, O., Y. Nimonkar, and Y. S. Shouche. 2013. Practice and prospects of microbial preservation. FEMS Microbiol. Lett. 339:19. https://doi.org/10.1111/1574-6968.12034.
Santivarangkna, C., U. Kulozik, and P. Foerst. 2008. Inactivation mechanisms of lactic acid starter cultures preserved by drying processes. J. Appl. Microbiol. 105:1-13. https://doi.org/10.1111/j .1365-2672.2008.03744.x.

Schwab, C., R. Vogel, and M. G. Ganzle. 2007. Influence of oligosaccharides on the viability and membrane properties of Lactobacillus reuteri TMW1.106 during freeze-drying. Cryobiology 55:108-114. https://doi.org/10.1016/j.cryobiol.2007.06.004.

Stefanello, R. F., E. H. Nabeshima, B. T. Iamanaka, A. Ludwig, L. L. M. Fries, A. O. Bernardi, and M. V. Copetti. 2019. Survival and stability of Lactobacillus fermentum and Wickerhamomyces anomalus strains upon lyophilisation with different cryoprotectant agents. Food Res. Int. 115:90-94. https://doi.org/10.1016/j .foodres.2018.07.044.

Su, J., X. Wang, W. Li, L. Chen, X. Zeng, Q. Huang, and B. Hu. 2018. Enhancing the viability of Lactobacillus plantarum as probiotics through encapsulation with high internal phase emulsions stabilized with whey protein isolate microgels. J. Agric. Food Chem. 66:12335-12343. https://doi.org/10.1021/acs.jafc.8b03807.

Velly, H., M. Bouix, S. Passot, C. Penicaud, H. Beinsteiner, S. Ghorbal, P. Lieben, and F. Fonseca. 2015. Cyclopropanation of unsaturated fatty acids and membrane rigidification improve the freezedrying resistance of Lactococcus lactis ssp. lactis TOMSC161. Appl. Microbiol. Biotechnol. 99:907-918. https://doi.org/10.1007/ s00253-014-6152-2

Wang, G., X. Yu, Z. Lu, Y. Yang, Y. Xia, P. F. H. Lai, and L. Ai. 2019. Optimal combination of multiple cryoprotectants and freezing-thawing conditions for high lactobacilli survival rate during freezing and frozen storage. Lebensm. Wiss. Technol. 99:217-223. https://doi.org/10.1016/j.lwt.2018.09.065.

\section{ORCIDS}

Guang-Qiang Wang (®) https://orcid.org/0000-0002-3966-044X Jing Pu ৫ https://orcid.org/0000-0003-3625-9367

Xiao-Qing Yu 으 https://orcid.org/0000-0001-8503-6034

Yong-Jun Xia (® https://orcid.org/0000-0002-2727-2730

Lian-Zhong Ai ํㅏ https://orcid.org/0000-0002-6681-9102 